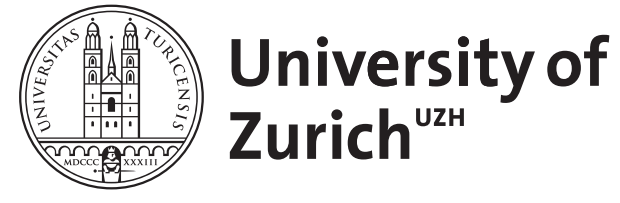
Archive

University of Zurich

University Library

Strickhofstrasse 39

CH-8057 Zurich

www.zora.uzh.ch

Year: 2015

\title{
When childhood ends: estimating the age of young people
}

Messelken, Daniel ; Crouse, Johan ; Winkler, David T

DOI: https://doi.org/10.1136/bmj.h6699

Posted at the Zurich Open Repository and Archive, University of Zurich

ZORA URL: https://doi.org/10.5167/uzh-116669

Journal Article

Published Version

Originally published at:

Messelken, Daniel; Crouse, Johan; Winkler, David T (2015). When childhood ends: estimating the age of young people. BMJ : British medical journal, 351:h6699.

DOI: https://doi.org/10.1136/bmj.h6699 


\title{
When childhood ends: estimating the age of young people
}

\author{
Doctors should tread carefully through this ethical minefield
}

\author{
Daniel Messelken researcher ${ }^{1}$, Johan Crouse legal adviser ${ }^{2}$, David T Winkler chair ${ }^{2}$
}

${ }^{1}$ Ethics Research Institute, Centre for Military Medical Ethics, University of Zürich, Zürich, Switzerland; ${ }^{2}$ ICMM Centre of Reference for Education on International Human Law and Ethics, Centre for Military Medical Ethics, Zürich

\begin{abstract}
Minors are increasingly reaching countries far from their homes as migrants, and their ages are often unknown. In Europe, up to 1500 people per country annually have medical examinations and procedures to estimate their chronological age. ${ }^{1}$ These procedures can cause considerable harm to individuals, particularly if performed without appropriate safeguards. Inappropriate age estimation may deter minors from applying for asylum in specific countries, and doctors may find themselves exploited in the service of migration policy. During missions, military doctors face demands to estimate the age of child soldiers destined for potentially unlawful detention or interrogation. Doctors therefore need to be aware of the limitations of medically estimating age and the associated ethical problems.
\end{abstract}

Medical estimation of age is still inaccurate and the results are unreliable. Best medical practice recommends a multidisciplinary approach including radiological, dental, and general medical assessments. ${ }^{2-4}$ But all these methods have wide margins of error. Age estimations have standard deviations of more than 12 months and are limited by intraindividual discrepancies, racial differences, and poor inter-rater reliability. The most recent approaches using computed tomography or magnetic resonance imaging have been studied in only a few very small cohorts. Current methods cannot rule out overestimating the age of individuals within the critical range of 16-20 years. ${ }^{5}$ Erroneous estimations based on wrist radiography recently led to the prolonged detention or even wrongful imprisonment of minors and triggered a governmental report by the Australian Human Rights Commission. ${ }^{6}$

Ethically, it is hard to justify treating someone as an adult based on such unreliable data. Furthermore, age estimation procedures, including intimate assessments of sexual maturity, can cause psychological distress and harm, particularly to adolescents who have been exposed to war and other traumas. Exposing children to radiation during imaging is also potentially harmful, even if the doses are small.

Against this backdrop, is age estimation ever justified? Ethical principles primarily oblige doctors to care for the health of their patients. Estimating the age of children does not therefore constitute a core task of any medical system. However, international regulations and national laws grant minors special protection, ${ }^{7}$ and age estimation might, at first sight, be considered appropriate to prevent adults accessing the limited resources reserved for minors. In such cases, use of age estimation is a political decision, and authorities must define a legal framework in which it will operate. However, politically and legally accepted regulations are not necessarily ethically just. Doctors must decide whether to refuse to participate for conscientious reasons

Age estimation can only be ethical in contexts where the protection and preferred treatment of minors is guaranteed according to international conventions. It is indefensible under any circumstances if the findings could potentially result in subsequent harsh interrogation, illegal imprisonment, or other serious harm.

The basic principles of medical ethics-informed consent, non-maleficence, and proportionality-must also be guaranteed. ${ }^{8}$ Genuine and voluntary informed consent is undermined when young migrants are forced to accept age estimation in order not to be considered adult. State authorities should develop sustainable approaches to managing the needs of young people, rather than get distracted by over-reliance on inaccurate estimations of age. ${ }^{10}$

Ethically, age estimation should therefore remain a method of last resort. If it must be done, then best practice principles should be applied diligently. Age must be estimated only by specifically trained doctors who are familiar with the evidence and have access to adequate technical equipment. Reports of age estimation must be clear and complete and respect medical confidentiality. They must include details of the methods used and their limitations, the findings, and a discussion of the likely margin of error. Individuals must be given the full benefit of the doubt and assigned the youngest possible age according to the examination findings. Reports must detail who made the estimate and advise on the possibility of appeal. Institutions 
performing age estimations should support an interdisciplinary network to ensure academic quality control.

Various European countries have begun to implement a more holistic approach, including structured interviews. ${ }^{18}$ They may not be any more accurate, but holistic approaches are ethically preferable because they focus on the maturity of the person and not on their chronological age, in line with the UN Convention on the Rights of the Child. More research is clearly desirable to develop more reliable, less harmful techniques and to improve holistic approaches to estimating age. For now, the widespread use of unreliable estimation remains ethically questionable.

Competing interests: We have read and understood BMJ policy on declaration of interests and have no relevant interests to declare.

Provenance and peer review: Not commissioned; externally peer reviewed.
1 European Asylum Support Office. Age assessment practice in Europe. European Union, 2014.

2 Black S, Payne-James J, Aggrawal A. Age estimation in the living: the practitioners guide. Wiley-Blackwell, 2010

3 Schmeling A, Grundmann C, Fuhrmann A, et al. Criteria for age estimation in living individuals. Int $J$ Legal Med 2008;122:457-60.

4 Bassed RB. Advances in forensic age estimation. Forensic Sci Med Pathol 2012;8:194-6.

5 Serinelli S, Panebianco V, Martino M, et al. Accuracy of MRI skeletal age estimation for subjects 12-19. Potential use for subjects of unknown age. Int $J$ Legal Med subjects 12-19. Potent
2015:129:609-17.

6 Australian Human Rights Commission. An age of uncertainty: inquiry into the treatment of individuals suspected of people smuggling offences who say that they are children. Australian Human Rights Commission, 2012.

7 United Nations. Convention on the Rights of the Child. 1989.

8 Aynsley-Green A, Cole TJ, Crawley H, et al. Medical, statistical, ethical and human rights considerations in the assessment of age in children and young people subject to immigration control. Br Med Bull 2012;102:17-42.

9 Thevissen PW, Kvaal SI, Willems G. Ethics in age estimation of unaccompanied minors. J Forensic Odontostomatol 2012;30(suppl 1):84-102.

10 Hjern A, Brendler-Lindqvist M, Norredam M. Age assessment of young asylum seekers. Acta Paediatrica 2012;101:4-7.

Cite this as: BMJ 2015;351:h6699

(c) BMJ Publishing Group Ltd 2015 